\title{
Perilaku Suami dalam Pengambilan Keputusan pada Ibu Bersalin ada Kasus Kegawat Daruratan Maternal di RSUD Koja Tahun 2018
}

\section{The Behavior of Husband's in Maternal Decision Making with Maternal Emergency in RSUD Koja Year 2018}

\author{
Dina Arihta $\mathrm{T}^{1}$, Rahayu Kristina ${ }^{2}$ \\ DIII Midwifery Study Program, STIKes Mitra RIA Husada, Jakarta \\ Jl. Karya Bhakti No.3, RT.8/RW.7, Cibubur, Ciracas, Jakarta 13720 \\ Telepon (021) 87750551 \\ Correspondence Email : ditabayu26@gmail.com
}

\begin{abstract}
Abstrak
Angka kematian ibu (AKI) merupakan salah salah satu indikator untuk melihat derajat kesehatan perempuan. $\mathrm{Di}$ indonesia penyebab kematian obstetri umumnya terkait dengan permasalahan gawat darurat obstetri, selain itu dapat disebabkan oleh keterlambatan suami dalam pengambilan keputusan sehingga berdampak pada kematian ibu. Tujuan penelitian ini untuk mengetahui cepat atau tidak suami dalam pengambilan keputusan pada kegawatdaruratan maternal.Penelitian ini menggunakan metode deskriptif dengan desain cross sectional. Jumlah populasi dalam penelitian ini yaitu 110 orang. Sampel pre eklamsi berat (PEB) sebanyak 52 responden diambil dengan teknik accidental sampling. Alat pengumpulan data yang digunakan adalah kuesioner. Analisis data menggunakan distribusi frekuensi dari cross table. Perilaku suami dalam pengambilan keputusan ibu bersalin dengan kasus kegawatdaruratan maternal menunjukkan sebagian besar responden lambat dalam pengambilan keputusan sebanyak 47 (90,4\%) orang dan sebagian kecil responden berperilaku cepat dalam pengambilan keputusan sebanyak $5(9,6 \%)$ orang . Perilaku suami dalam pengambilan keputusan kegawatdaruratan maternal dalam kategori lambat.
\end{abstract}

Kata kunci : Kegawatdaruratan maternal, pengambilan keputusan suami

\begin{abstract}
Maternal mortality is one indicator to see the degree of health of women. In indonesia, the cause of obstetric mortality commonly associated with obstetric emergency problems other than that can be caused by the delay of the husband in taking so that the impact on maternal mortality. This study purpose is to find out whether or not the husband in decision making in emergency maternal. The study uses descriptivemethod with cross sectional design, the population in the study is 110 people. The pre eklampsia sample is 52 respondents who was taken by a accidental sampling. The collection of data used is a questionnaire. The analysis data in the distribution of the cross the table. The husband's behavior in making decisions on maternal emergency cases shows the slow category found in $47(90,4 \%)$ respondents and a small part of respondent behave quickly (5 or 9,6\%
\end{abstract}


respondents). The husband' behavior in making the maternal emergency decision is in the slow category.

Key Words : maternal emergency, husband decision making

\section{Pendahuluan}

Salah satu indikator penentu derajat kesehatan adalah angka kematian ibu (AKI). Dalam pencapaian Millenium Development Goals (MDGs), telah dilakukan berbagai upaya yang terencana dan di tuangkan dalam Rencana Pembangunan Jarak menengah (RPJM) tahun 2010-2014. Salah satu sasaran yang telah di tetapkan yaitu target menurunkan AKI pada tahun 2014 menjadi 118/100.000 kelahiran hidup. Berdasarkan Laporan Pencapaian MDGs Indonesia 2013 tahun 2007, AKI di indonesia masih cukup tinggi yaitu 228/100.000 kelahiran hidup dan pada tahun 2012 mengalami peningkatan menjadi 359/100.000 kelahiran hidup. Target MDGs tahun 2015 dalam menurunkan AKI menjadi 102/100.000 kelahiran hidup.

Kematian ibu dapat disebabkan oleh banyak faktor. Penyebab kematian ibu paling umum di Indonesia adalah penyebab obstetri langsung yaitu perdarahan $28 \%$, preeklampsia/eklampsia $24 \%$, infeksi $11 \%$, sedangkan penyebab tidak langsung adalah trauma obstetri 5\% dan lain-lain (WHO, 2007).

Selain faktor-faktor penyebab kematian maternal tersebut, kematian maternal dapat disebabkan oleh cepat atau tidaknya dalam pengambilan keputusan di dalam keluarga (suami) sehingga menyebabkan keterlambatan dalam pengambilan keputusan. Keterlambatan pengambilan keputusan di sebabkan oleh suami terlambat mengenali resiko tinggi pada ibu bersalin, terlambat dalam mencari pertolongan persalinan, terlambat dalam mencari transportasi, dan terlambat mengambil keputusan ke rumah sakit sehingga menyebabkan kegawatdaruratan (Fibriana, 2007).

Kegawatdaruratan adalah situasi serius dan berbahaya yang terjadi secara tiba-tiba dan tidak terduga sehingga membutuhkan tindakan segera untuk menyelamatkan jiwa atau nyawa (Novvi, dkk. 2016). Oleh karena ituperawatan selama persalinan dan kehamilan yang telah di perbaiki dapat mengurangi kematian maternal 50-80\%. Perbaikan aspek sosial, budaya ekonomi, dan pendidikan dapat membantu mengatasi $64 \%$ penyebab kematian ibu. Kepercayaan tradisional yang dianut masyarakat tertentu akan mempengaruhi pengambilan keputusan oleh suami sebagai kepala keluarga atau orang yang memegang peranan penting dalam pengambilan keputusan. Akibatnya jika terjadi kasus kegawatdaruratan pada ibu hamil, melahirkan atau setelah melahirkan harus melibatkan beberapa pihak untuk berembuk. Hal ini akan menyebabkan terjadinya keterlambatan pengambilan keputusan yang mengakibatkan kematian pada ibu, oleh karena itu suami harus tepat dan efektif dalam pengambilan keputusan (Sadiah, 2012).

Perilaku merupakan segala macam pengalaman serta interaksi manusia dengan lingkungannya yang terwujud dalam bentuk pengetahuan, sikap, dan tindakan. Perilaku suami dalam pengambilan keputusan ibu bersalin dengan kasus kegawatdaruratan maternal sangat dibutuhkan karena suami merupakan penentu pengambilan keputusan 
untuk ditanganinya kasus kegawatdaruratn pada ibu. Oleh karena itu suami harus bisa mengambil keputusan yang tepat dan efektif (Sarwono, 2014).

Pengambilan keputusan yang tepat dan efektif dalam penanganan persalinan dan komplikasi berdampak terhadap penurunan angka kesakitan dan kematian ibu di Indonesia. Salah satunya ibu menghadapi proses persalinan oleh tenaga kesehatan professional dan terlatih dalam penanganan persalinan dan komplikasi serta pada tempat persalinan yang aman. Ibu dan keluarga menjadi mau, tanggap dan mampu membuat keputusan untuk memanfaatkan petugas kesehatan dan fasilitas kesehatan (Roost, et al., 2009).

Dampak dari pengambilan keputusan yang tepat adalah mencegah terjadinya keterlambatan. Pada keterlambatan ini diantaranya; terlambat mengenal risiko tinggi dan bahaya pada kehamilan dan persalinan, terlambat mengambil keputusan untuk mencari pertolongan persalinan dan penanganan kompilkasi oleh tenaga kesehatan di pelayanan pra rujukan maupun rujukan sehingga kasus kegawatdaruratan bisa cepat di tangani (Path, 2010).

Menurut survei data di RSUD Koja pada tahun 2016 angka kejadian kegawatdaruratan tertinggi pada diagonosa PEB sebesar $16,52 \%$. Pada tahun 2017 angka kejadian kegawatdaruratan diagnosa PEB mengalami peningkatan menjadi $17,22 \%$.

Data survei awal pada suami saat pengambilan keputusan pada ibu bersalin dengan kasus kegawatdaruratan maternal di RSUD Koja tanggal 05 April 2018, terdapat 10 suami dari ibu bersalin yang mengalami kasus kegawatdaruratan maternal diantaranya ada 3 suami yang cepat dalam pengambilan keputusan, dan 7 suami yang lambat dalam pengambilan keputusan. Untuk itu, peneliti tertarik untuk melakukan penelitian tentang "Gambaran perilaku suami dalam pengambilan keputusan pada ibu bersalin dengan kasus kegawatdaruratan maternal di RSUD Koja tahun 2018".

\section{Bahan dan Metoda Penelitian}

Metode penelitian ini adalah deskriftif dengan desain cross sectional Jumlah populasi dalam penelitian sebanyak 110 orang. Sampel pre eklamsi berat (PEB) yang didapat sebanyak 52 responden yang diambil dengan teknik accidental sampling. Alat pengumpulan data yang digunakan adalah kuesioner. Analisis data menggunakan distribusi frekuensi dari cross table.

\section{Waktu dan Tempat}

Adapun lokasi dan waktu penelitian ini di lakukan di RSUD Koja pada bulan April 2018. Pengambilan data secara primer dengan menggunakan kuesioner. Adapun variabel yang akan diteliti adalah pengetahuan, pendidikan, pendapatan, sumber informasi, peran suami.

\section{Hasil Penelitian}

Tabel 1. menunjukkan dari 52 responden suami yang berperilaku cepat dalam pengambilan keputusan sebanyak 5 responden $(9,6 \%)$ dan lambat dalam mengambil keputusan sebanyak 47 responden $(90,4 \%)$, ditinjau dari pengetahuan sebagian besar responden yang berpengetahuan kurang sebanyak 43 responden $(82,7 \%)$ yang berpengetahuan baik sebanyak 9 responden $(17,3 \%)$, dari frekuensi pendidikan sebagian besar responden berpendidikan rendah sebanyak 29 responden (55,8\%) sedangkan yang berpendidikan tinggi sebanyak 23 responden $(44,2 \%)$, dari frekuensi pendapatan 
sebagian besar responden memiliki pendapatan yang tinggi sebanyak 37 responden $(71,1 \%)$ sedangkan pendapatan rendah sebanyak 15 responden $(28,9 \%)$, dari frekuensi sumber informasi sebagian besar responden mendapatkan informasi melalui media elektronik sebanyak 40 responden (77\%) sedangkan dari media cetak sebanyak 12 responden (23\%), dari frekuensi peran suami hampir seluruh suami berperan dalam pengambilan keputusan sebanyak 52 responden (100\%).

Distribusi gambaran perilaku suami dalam pengambilan keputusan berdasarkan pengetahuan sebagian besar responden yang memiliki perilaku lambat dalam pengambilan keputusan dengan pengetahuan yang kurang sebanyak $80,8 \%$.

Distribusi gambaran perilaku suami dalam pengambilan keputusan berdasarkan pendidikan sebagian besar responden yang memiliki perilaku lambat dalam pengambilan keputusan dengan pendidikan yang rendah sebanyak $51,9 \%$.
Distribusi gambaran perilaku suami dalam pengambilan keputusan berdasarkan pendapatan sebagian besar responden yang memiliki perilaku lambat dalam pengambilan keputusan dengan pendapatan yang tinggi sebanyak $67,3 \%$.

Distribusi gambaran perilaku suami dalam pengambilan keputusan berdasarkan sumber informasi sebagian besar responden yang memiliki perilaku lambat dalam pengambilan keputusan mendapatkan sumber informasi melalui media elektronik sebanyak $71,1 \%$.

Distribusi gambaran perilaku suami dalam pengambilan keputusan berdasarkan peran suami hampir seluruh suami yang berperan lambat dalam pengambilan keputusan sebanyak $90,4 \%$.

Selain itu, data lain mengenai tingkat pengetahuan, pendidikan pendapatan, sumber informasi dan peran suami (Tabel 2-6) dimana data-data tersebut sebagai data pendukung dari penelitian ini yang akan dibahas dalam bab diskusi.

Tabel 1. Distribusi frekuensi perilaku pengambilan keputusan, pengetahuan, pendidikan, pendapatan, sumber informasi, peran suami di RSUD Koja Jakarta tahun 2018

\begin{tabular}{ccc}
\hline Variabel & Jumlah & Persentase $(\%)$ \\
\hline Perilaku pengambilan keputusan & & $\%$ \\
$\quad$ Cepat & 5 & $9,6 \%$ \\
$\quad$ Lambat & 47 & $90,4 \%$ \\
Pengetahuan & 9 & $17,3 \%$ \\
$\quad$ Baik & 93 & $82,7 \%$ \\
Kurang & & \\
Pendidikan & 23 & $44,2 \%$ \\
$\quad$ Tinggi & 29 & $55,8 \%$ \\
$\quad$ Rendah & 37 & $71,1 \%$ \\
Pendapatan & 15 & $28,9 \%$ \\
$\quad$ Tinggi & & \\
$\quad$ Rendah & 40 & $77 \%$ \\
Sumber informasi & $23 \%$ \\
$\quad$ Media Elektronik & 12 & $100 \%$ \\
Media cetak & & $0 \%$ \\
Peran suami & 52 & \\
Berperan & 0 & \\
Tidak berperan & & \\
\hline & &
\end{tabular}


Tabel 2. Distribusi Frekuensi Gambaran perilaku suami dalam pengambilan keputusan ibu bersalin dengan kasus kegawatdaruratan maternal di RSUD Koja berdasarkan Pengetahuan

\begin{tabular}{lcccccc}
\hline \multirow{2}{*}{ Pengetahuan } & \multicolumn{3}{c}{ Perilaku pengambilan keputusan } & \multicolumn{3}{c}{ Total } \\
\cline { 2 - 6 } & \multicolumn{2}{c}{ Cepat } & \multicolumn{2}{c}{ Lambat } & & \\
\cline { 2 - 6 } & $\mathrm{n}$ & $\%$ & $\mathrm{n}$ & $\%$ & $\mathrm{~N}$ & $\%$ \\
\hline Baik & 4 & $7,7 \%$ & 5 & $9,6 \%$ & 9 & $17,3 \%$ \\
Kurang & 1 & $1,9 \%$ & 42 & $80,8 \%$ & 43 & $82,7 \%$ \\
\hline Jumlah & 5 & $9,6 \%$ & 47 & $90,4 \%$ & 52 & $100 \%$ \\
\hline
\end{tabular}

Tabel 3. Distribusi Frekuensi Gambaran perilaku suami dalam pengambilan keputusan ibu bersalin dengan kasus kegawatdaruratan maternal di RSUD Koja berdasarkan Pendidikan

\begin{tabular}{lcccccc}
\hline \multirow{2}{*}{ Pendidikan } & \multicolumn{3}{c}{ Perilaku pengambilan keputusan } & \multicolumn{3}{c}{ Total } \\
\cline { 2 - 5 } & \multicolumn{2}{c}{ Cepat } & \multicolumn{2}{c}{ Lambat } & & \\
\cline { 2 - 6 } & $\mathrm{n}$ & $\%$ & $\mathrm{n}$ & $\%$ & $\mathrm{~N}$ & $\%$ \\
\hline Tinggi & 3 & $5,7 \%$ & 20 & $38,4 \%$ & 23 & $44,1 \%$ \\
Rendah & 2 & $4 \%$ & 27 & $51,9 \%$ & 29 & $55,9 \%$ \\
\hline Jumlah & 5 & $9,7 \%$ & 47 & $90,3 \%$ & 52 & $100 \%$ \\
\hline
\end{tabular}

Tabel 4. Distribusi Frekuensi Gambaran Perilaku Suami dalam Pengambilan Keputusan Ibu Bersalin dengan Kasus Kegawatdaruratan Maternal di RSUD Koja berdasarkan Pendapatan

\begin{tabular}{lcccccc}
\hline Pendapatan & \multicolumn{2}{c}{ Perilaku pengambilan keputusan } & \multicolumn{2}{c}{ Total } \\
\cline { 2 - 5 } & \multicolumn{2}{c}{ Cepat } & \multicolumn{2}{c}{ Lambat } & & Nam \\
\hline Tinggi & $\mathrm{n}$ & $\%$ & $\mathrm{n}$ & $\%$ & $\mathrm{~N}$ & $\%$ \\
Rendah & 2 & $3,9 \%$ & 35 & $67,3 \%$ & 37 & $71,2 \%$ \\
Jumlah & 3 & $5,8 \%$ & 12 & $23 \%$ & 15 & $28,8 \%$ \\
\hline
\end{tabular}

Tabel 5. Distribusi Frekuensi Gambaran Perilaku Suami Dalam Pengambilan Keputusan Ibu Bersalin Dengan Kasus Kegawatdaruratan Maternal di RSUD Koja berdasarkan Sumber Informasi

\begin{tabular}{|c|c|c|c|c|c|c|}
\hline \multirow[t]{3}{*}{ Sumber informasi } & \multicolumn{4}{|c|}{ Perilaku pengambilan keputusan } & \multirow{2}{*}{\multicolumn{2}{|c|}{ Total }} \\
\hline & \multicolumn{2}{|c|}{ Cepat } & \multicolumn{2}{|c|}{ Lambat } & & \\
\hline & $\mathrm{n}$ & $\%$ & $\mathrm{n}$ & $\%$ & $\mathrm{~N}$ & $\%$ \\
\hline Media elektronik & 3 & $5,8 \%$ & 37 & $71,1 \%$ & 40 & $76,9 \%$ \\
\hline Media cetak & 2 & $3,9 \%$ & 10 & $19,2 \%$ & 12 & $23,1 \%$ \\
\hline Jumlah & 5 & $9,7 \%$ & 47 & $90,3 \%$ & 52 & $100 \%$ \\
\hline
\end{tabular}

Tabel 6. Distribusi Frekuensi Gambaran Perilaku Suami Dalam Pengambilan Keputusan Ibu Bersalin Dengan Kasus Kegawatdaruratan Maternal di RSUD Koja berdasarkan Peran Suami

\begin{tabular}{|c|c|c|c|c|c|c|}
\hline \multirow{3}{*}{ Peran Suami } & \multicolumn{4}{|c|}{ Perilaku pengambilan keputusan } & \multirow{2}{*}{\multicolumn{2}{|c|}{ Total }} \\
\hline & \multicolumn{2}{|c|}{ Cepat } & \multicolumn{2}{|c|}{ Lambat } & & \\
\hline & $\mathrm{n}$ & $\%$ & $\mathrm{n}$ & $\%$ & $\mathrm{~N}$ & $\%$ \\
\hline Berperan & 5 & $9,6 \%$ & 47 & $90,4 \%$ & 52 & $100 \%$ \\
\hline Tidak berperan & 0 & $0 \%$ & 0 & $0 \%$ & 0 & $0 \%$ \\
\hline Jumlah & 5 & $9,6 \%$ & 47 & $90,4 \%$ & 52 & $100 \%$ \\
\hline
\end{tabular}




\section{Diskusi}

\section{Perilaku suami dalam pengambilan}

\section{keputusan kegawatdaruratan maternal}

Berdasarkan hasil penelitian yang telah dilakukan didapatkan bahwa perilaku suami dalam pengambilan keputusan ibu bersalin dengan kegawatdaruratan maternal sebagian besar responden lambat dalam pengambilan keputusan.

Hal ini berbeda dengan teori Notoatmodjo (2010), yang mengatakan bahwa perilaku suami dalam pengambilan keputusan kegawatdaruratan berarti suatu respon suami dalam bentuk sikap dan tindakan untuk menghadapi kegawatdaruratan maternal. Oleh karena itu suami harus bisa mengambil keputusan yang cepat, tepat dan efektif.

Hasil penelitian ini sesuai bila dibandingkan dengan penelitian Sadiah (2012), yaitu dari 7 orang responden 5 orang ibu menerima proses rujukan, dimana 3 orang sebelumnya tidak langsung dibawa ke tenaga kesehatan terdekat sehingga pengambilan keputusan yang diambil lambat Menurut asumsi peneliti bahwa perilaku suami yang lambat dalam pengambilan keputusan itu disebabkan oleh beberapa banyak faktor atau kurangnya kesadaran dari suami tersebut akan pentingnya pengambilan keputusan secara cepat, sehingga keputusan yang di ambil suami itu lambat.

\section{Pengetahuan}

Berdasarkan hasil penelitian yang telah dilakukan, ditinjau dari perilaku suami yang lambat dalam mengambil keputusan sebagian besar terdapat pada responden yang memiliki pengetahuan kurang.

$$
\text { Menurut Notoatmodjo }
$$
pengetahuan merupakan hasil "tahu" dan terjadi setelah orang melakukan penginderaan terhadap suatu objek tertentu. Pengetahuan yang baik akan mendasari perilaku seseorang secara terus menerus. Berdasarkan hasil penelitian bahwa pengetahuan mengenai resiko tinggi dan komplikasi obstetri saat persalinan (kegawatdaruratan) mempengaruhi terjadinya keterlambatan dalam mengambil keputusan mencari pertolongan, terutama penanganan kesehatan (Jammeh et al., 2011). Hal ini sesuai dengan penelitian Hani Sadiah 2012 yaitu sebagian besar dari responden pada penelitian ini menyatakan belum mengetahui dan salah satunya adalah lupa mengenai tanda bahaya kehamilan dan persalinan sehingga lambat dalam pengambilan keputusan.

Berdasarkan teori dan hasil penelitian terdapat kesesuain yang menunjukan bahwa masih rendahnya pengetahuan suami tentang kegawatdaruratan maternal (tanda bahaya kehamilan dan persalinan). Menurut asumsi peneliti kurangnya pengetahuan suami mungkin dikarenakan kurangnya informasi tentang tanda bahaya kehamilan maupun persalinan sehingga tidak semua suami mengetahui tentang kegawatdaruratan (tanda bahaya kehamilan dan persalinan) sehingga lambat dalam pengambilan keputusan.

\section{Pendidikan}

Berdasarkan hasil penelitian yang telah dilakukan, ditinjau dari perilaku yang lambat dalam mengambil keputusan sebagian besar terdapat pada responden yang berpendidikan rendah sebanyak $51,9 \%$.

Hal ini sesuai dengan teori Notoatmodjo (2010) pendidikan adalah suatu usaha untuk mengembangkan kepribadian dan kemampuan di dalam dan di luar sekolah dan berlangsung seumur hidup. Pendidikan dapat mempengaruhi seseorang termasuk perilaku seseorang dalam mengambil keputusan. Sadiah 2012 menjelaskan pendidikan suami yang rendah 
akan lambat dalam mengambil keputusan. Dalam hal ini peneliti berasumsi bahwa pendidikan suami mempengaruhi perilaku seseorang untuk berperilaku atau mengambil keputusan kegawatdaruratan maternal.

\section{Pendapatan}

Berdasarkan hasil penelitian yang telah dilakukan, ditinjau dari perilaku yang lambat dalam mengambil keputusan sebagian besar terdapat pada responden yang memiliki pendapatan tinggi. Hal itu tidak sesuai dengan teori yaitu faktor ekonomi pada umumnya menggambarkan tingkat kesejahteraan suatu keluarga. Faktor ekonomi berhubungan secara tidak langsung dengan perilaku mereka yang berasal dari ekonomi rendah, pada umumnya memiliki tingkat pendidikan rendah dan pengetahuan yang kurang, pada akhirnya berpengaruh pada perilaku mereka (Notoatmodjo, 2007).Penelitian ini tidak sesuai dengan Sadiah 2012 bahwa pendapatan suami yang rendah akan lambat dalam pengambilan keputusan. Peneliti berasumsi dari hasil penelitian terdapat ketidaksesuaian antara teori dan penelitian sebelumnya bahwa pendapatan tidak berpengaruh terhadap perilaku responden dalam mengambil keputusan.

\section{Sumber informasi}

Berdasarkan hasil penelitian yang telah dilakukan, ditinjau dari perilaku yang lambat dalam mengambil keputusan sebagian besar terdapat pada responden yang mendapatkan informasi melalui media elektronik.Hal ini tidak sesuai dengan teori menurut Notoatmodjo (2003) bahwa semakin banyak informasi dapat mempengaruhi atau menambah pengetahuan seseorang dan dengan pengetahuan menimbulkan kesadaran yang akhirnya seseorang akan berperilaku sesuai dengan pengetahuan yang dimilikinya.
Penelitian ini juga tidak sesuai dengan penelitian Sadiah (2012) bahwa ibu atau suami yang menerima sumber informasi melalui membaca buku kesehatan ibu dan anak (melalui media cetak) lambat dalam pengambilan keputusan. Menurut asumsi peneliti bahwa suami lebih mengerti apabila dijelaskan oleh tenaga kesehatan karena lebih menguasai materi daripada membaca sehingga mempengaruhi suami dalam pengambilan keputusan.

\section{Peran suami}

Berdasarkan hasil penelitian yang telah dilakukan, ditinjau dari perilaku yang lambat dalam mengambil keputusan yaitu mayoritas pada suami yang berperan dalam pengambilan keputusan. Hal ini sesuai dengan penelitian Sadiah (2012) suami memberikan perannya sebagai kepala keluarga yang menjamin kehidupan istrinya. Akan tetapi suami lambat dalam mengambil keputusan.

Hasil penelitian ini tidak sesuai dengan teori menurut Hafidz (2007) Peran suami dalam menghadapi kegawatdaruratan sangat dibutuhkan peran aktifnya. Pada kegiatan program suami siaga terdapat amanat persalinan, bertujuan untuk perencanaan penanganan persalinan dan komplikasi yang kemungkinan terjadi. Setiap persalinan telah dipersiapkan baik dari segi psikologis, maupun material. Hal ini bertujuan agar tidak terjadi keterlambatan dalam penanganan kasus komplikasi obstetri saat persalinan.Menurut asumsi peneliti bahwa peran suami berpengaruh terhadap pengambilan keputusan kegawatdaruratan maternal.

\section{Simpulan}

Berdasarkan hasil penelitian Perilaku suami dalam pengambilan keputusan ibu bersalin dengan kasus kegawatdaruratan 
maternal adalah :lambat dalam pengambilan keputusan yang disebabkan .

1. pengetahuan yang kurang,

2. berpendidikan rendah

3. pendapatan tinggi,

Sumber informasi responden melalui media elektronik dan mayoritas suami berperan dalam pengambilan keputusan.

\section{Saran}

Tenaga kesehatan lebih meningkatkan lagi konseling tentang tanda-tanda bahaya pada kehamilan maupun persalinan untuk mengantisipasi agar pengambilan keputusan lebih cepat lagi sehingga menurunkan resiko kematian pada ibu.

\section{Daftar Pustaka}

Fibriana Al. 2007. Faktor-faktor risiko yang mempengaruhi kematian maternal (studi kasus di kabupaten Cilacap). Tesis. Pasca Sarjana Magister Epidemiologi Universitas Diponegoro Semarang. 76-154.

Hafidz EM. 2007. Hubungan peran suami dan orang tua dengan perilaku ibu hamil dalam pelayanan antenatal dan persalinan di wilayah Puskesmas Kecamatan Sedan Kabupaten Rembang. Jurnal Promosi Kesehatan Indonesia. 2 (2): 87-97.

Jammeh A, Sundby J \& Vangen S. 2011. 'Maternal and obstetric risk factors for low birth weight and preterm birth in rural Gambia: a hospital-based study of 1579 deliveries'. Journal of Obstetrics and Gynecology. 1: 94-103.

Notoatmodjo. 2003. Pendidikan dan perilaku kesehatan. Jakarta : Rineka Cipta

Notoatmodjo. 2010. Promosi Kesehatan Teori dan Aplikasi. Jakarta: Rineka Cipta

Notoatmodjo S. 2011. Kesehatan Masyarakat IImu dan Seni. Jakarta: Rineka Cipta

Novvi K, Ermalinda E, Pratiwi WM. 2016. Asuhan Kebidanan Kegawatdaruratan Maternal dan Neonatal. In Media, Jakarta.

PATHS (Partnership for Transforming Health Systems). 2010. Increasing access to safe motherhood services. Technical Brief, UK Department for International Development (DFID). Population Reports (PR).

Roost M, Jonsson C, Liljestand J. 2009. A quality study of maternal care seeking behaviour for near miss morbidity in bolivia.. Reproductive Health 6(1):13

Sadiah H. 2012. Kajian pengambilan keputusan dalam proses rujukan ibu dengan komplikasi obstetri saat persalinan di RSSIB RSUD Cianjur tahun 2012. Sripsi. Fakultas Kesehatan Masyarakat. Universitas Indonesia. 59-116.

Sarwono P. 2013. IImu Kebidanan, (Jakarta : PT Bina Pusaka. 527 